\title{
Reflecting on and Articulating Teaching Experiences: Academics Learning to Teach in Practice
}

\author{
Mette Sandoff ${ }^{1}$, Kerstin Nilsson ${ }^{2,}$ Britt-Marie Apelgren ${ }^{3}$, Sylva Frisk $^{4} \&$ Shirley Booth $^{5}$ \\ ${ }^{1}$ Department of Business Administration, University of Gothenburg, Gothenburg, Sweden \\ ${ }^{2}$ Institute of Health and Care Sciences, Sahlgrenska Academy at University of Gothenburg, Gothenburg, Sweden \\ ${ }^{3}$ Department of Education and Special Education, University of Gothenburg, Gothenburg, Sweden \\ ${ }^{4}$ School of Global Studies, University of Gothenburg, Gothenburg, Sweden \\ ${ }^{5}$ Department of Pedagogical, Curricular and Professional Studies, University of Gothenburg, Gothenburg, Sweden \\ Correspondence: Kerstin Nilsson, Box 457, SE 40530 Gothenburg, Sweden. Tel: 46-(0)70-858-9464. E-mail: \\ kerstin.nilsson@fhs.gu.se
}

Received: November 15, 2018

Accepted: December 15, 2018

Online Published: December 19, 2018

doi:10.5430/ijhe.v7n6p139

URL: https://doi.org/10.5430/ijhe.v7n6p139

\begin{abstract}
Higher education teaching demands theoretical and practical knowledge. It goes without saying, a strong knowledge of one's subject is essential. But while teaching principles are generally gleaned from short courses, it is one's own teaching that offer the main ground for gaining practical teaching knowledge. To examine this claim we have conducted an interview-study in which Swedish business administration academics have described where they learned something about their teaching. An interpretative analysis led to six different lessons learned, ranging from the personal, through the pedagogical, to the interpersonal. We claim there are three necessary opportunities to turn the experience into an occasion for learning: reflection over experience, the opportunity to articulate one's experience, and a forum for sharing; particularly experiences connected with risk-taking. We conclude that academics need opportunities to reflect on and articulate their learning experiences related to the practices of teaching, and to share and discuss them with colleagues.
\end{abstract}

Keywords: experience-based learning, reflection and articulation of experience, practical teaching competence, risk-taking, higher education

\section{Introduction and Purpose}

There are few studies of how pedagogical development processes come about in practice. Accordingly, we have carried out a study related to this issue by taking teaching experiences as a point of departure, asking business administration academics to describe situations when they learned something about their own teaching based on experience. Throughout this paper we will refer to the teachers we have interviewed as "academics" to imply that they both teach and conduct research. Thus, the focus of the study is academics' experiences of how different teaching situations contributed to developing their practical teaching competence.

Research on experience-based learning in general has shown that, besides courses in pedagogical development, learning from everyday practice is influential. For example, Price and colleagues explored how professionals use existing skills and former experience in shaping their current work and developing their practice (Price, Scheeres, \& Boud, 2009). The relationship between academics' approaches to teaching, and to students' learning, has been shown to be context-dependent (Ramsden, 2003; Ramsden, Prosser, Trigwell, \& Elaine Martin, 2007; Trigwell \& Prosser, 2014). Academics focusing on student-centred learning and student responsibility have, for example, been found to adhere more holistically to intended learning outcomes in their teaching. To enhance pedagogical development, researchers have argued that learning from pedagogical courses needs to be experienced, tested and refined via practical use in order to result in developed teaching skills and increased competence among academics (Daniels, 2017; Kemmis, 2012; Kolb, 1984).

Academics develop their pedagogical skills, competence and wisdom via experience-based learning, when interacting with students, in discussions with colleagues and by their own reflection (Daniels, 2017; Webster-Wright, 2009). According to Vithal a continuous cycle of improvement is maintained when both reflection and action are 
included (Vithal, 2016). Thus, reflecting on and learning from one's own teaching expertise is crucial. McAlpine and colleagues point to effective development as an academic coming about through the ongoing process of reflection, monitoring the situation and making decisions grounded in prior teaching knowledge (McAlpine, Weston, Berthiaume, Fairbank-Roch, \& Owen, 2004). The development of practice occurs through 'acting in praxis' (Ellström \& Kock, 2011; Eraut, 2004; Kemmis, 2012).

Academics as teachers are influenced by their prior learning from pedagogical courses and teaching experiences, how they think of teaching, as well as instructional and contextual factors when developing their pedagogical competence (Oleson \& Hora, 2014). However, developing pedagogical practice may be hampered if academics lack the will to take risks. If risk-taking is perceived as too dangerous, they will probably not participate in pedagogical development, thereby hindering their own pedagogical competence development (Le Fevre, 2014).

Malcolm and Zukas (2009) highlighted the messiness of academic work, in terms of encompassing research, teaching and service requiring different skills. They called for a deepened understanding of prevailing conditions, especially for academics involved in teaching (Malcolm \& Zukas, 2009). Underlining this, Leibowitz called for a desirable shift in the meaning of 'academic development' and concluded that when narrowing down to the education part of academic development, it has become common to refer only to student learning, rather than academics' learning (Leibowitz, 2014).

The results from this study may hopefully contribute to this endeavour and benefit possibilities for competence development among academics, improved pedagogical development as well as sustainable organizational learning environments. Accordingly, the purpose of this study is to gain deeper understanding of academics' experiences of teaching situations that they consider to have contributed to developing their practical teaching competence.

\section{Method}

In accord with our purpose, the study has adopted a qualitative approach when collecting data by interviewing a selection of academics (Patton, 2002). The interviews started with an invitation to the participant to describe a situation that she/he had experienced as learning. The participants were free to describe several situations. By conducting interviews centred on such situations gave the participants the opportunity to fully describe teaching situations they had experienced, thereby providing information about behaviours, reactions and learning in different situations (Silverman, 2013).

\subsection{Participants}

The empirical setting for this study involved academics from the Department of Business Administration, at a large Swedish University. Twenty participants were voluntarily and randomly recruited from a complete list of the academics employed full-time (i.e. senior lecturers), in total 64. All participants had a doctoral degree in Business Administration (15 persons) or in Philosophy (5 persons). The department was organized in several sub-groups representing different areas of specialization. In order to obtain variation in the experiences of learning through practice, both men ( 12 persons) and women ( 8 persons) from the different sub-groups were recruited. Their mean age was 43 and they had on average 11 years' experience of teaching.

Neither the law (Act 1992:1434 (Amended SFS 2017:279)) nor the ordinance (Ordinance 1993:100 (Amended SFS 2017:844)) regulating higher education in Sweden, specifies pedagogical learning requirements for academics. However, in recent years, many of the Swedish higher education institutions have specified pedagogical learning requirements in their own Employment Procedures. According to the Employment Procedure of the university in this study, 20 credits of courses in pedagogical development, to include both undergraduate teaching and doctoral supervision, were required for academics involved in teaching. All except one person had the required credits and they all described themselves as being experienced or very experienced in teaching.

\subsection{Data Collection}

Data was collected by interviewing the participants in their offices at convenient times of their own choice. The participants were contacted by telephone beforehand and asked if they wanted to participate. An e-mail with information about the purpose of the study, the method used, some examples of interview questions as well as a request to prepare themselves in terms of recalling situations where they might have learned something about their teaching, was sent to them. Written consent was obtained from all participants, and they were informed that they could withdraw at any time without giving any explanation. Thus the study has been conducted in accordance with the ethical rules current in Swedish legislation (Act 2003:460 (Amended SFS 2008:192)). 
The participants were asked to describe teaching situations they experienced have had an impact on their pedagogical learning and competence development. After some introductory background questions, a typical starting question was: 'Could you please tell me about a teaching situation?' A typical follow-up question was: 'What do you consider you learned from that situation and how did that come about?' Questions to achieve further clarification were asked with the aim of obtaining detailed descriptions of high quality and relevance. The interviews lasted approximately 30 to 60 minutes. They were recorded, transcribed verbatim, and immediately anonymized after completion. A total of 53 situations were collected which is assumed to be a sufficient number for saturation of meaning (Silverman, 2013).

\subsection{Analysis}

A qualitative, interpretative analysis of the interviews was used (Patton, 2002). The analysis process took its point of departure in the purpose of the study, namely to investigate how different teaching situations were thought to contribute to the development of practical teaching competence. The first step included reading through all the transcripts in order to become familiar with the entire material. Thereafter the interview texts were imported into the NVivo 10.0 program (software for qualitative analysis QSR International Pty Ltd). To capture the meaning of the texts, meaningful segments or units in the text were identified, tagged and subsequently sorted into appropriate thematic groups.

The analysis was conducted as an iterative process between the researchers, all experienced academics from different disciplines, including one from the discipline of business administration. Their previous diverse experience of conducting qualitative research studies, including CIT-studies, favourably promoted the work of understanding and interpreting the participants' descriptions, while being aware that pre-understanding and being knowledgeable in the area of study can also jeopardize the researcher's possibility to stay neutral. Awareness, conscious reflection and continuous discussions about 'correct' interpretations versus assumed ones (Patton, 2002) have helped in the endeavour to allow the text to stand for itself during the analytical process.

\section{Results}

In this section the collected data is presented as organised into six themes (A-F) that emerged from the interpretative analysis. Each theme depicts representative examples of experience-based learning and the learning outcomes as found in the participants' descriptions of teaching situations. We present now the themes, illustrated with excerpts from the interviews and marked with an identification code, 1-20. The themes are ordered with reference to one main dimension - from focusing on learning about oneself as an academic and performer, to focusing on one's students as learners. There is also a dimension of risk-taking, from caution to acknowledging and coping with risk.

\subsection{Learning that Preparation Promotes an Open Approach and Gives Confidence (A)}

Participants described the importance of preparation, especially for junior academics, as well as of learning from the students. The questions raised exemplified which parts of their teaching students found tricky and therefore in need of further clarification. Being well prepared in combination with a sensitive approach gave participants a certain degree of self-confidence as academics.

One participant described the preparation part as a first and necessary step in a musical act, but the main part of the act as being impossible to prepare in advance; one had to rely on one's tacit knowledge:

How I prepare? Hm, read as much as possible, the case and the slides and so on, but I improvise quite a lot. It's like jazz, you have to be able to play the instrument and you have to be able to read the music and feel the beat, but how should you prepare a trumpet solo, it's not possible to prepare $|\ldots|$ but of course you have all that backing with all the material. (11)

Even though preparation was mostly described as necessary for doing a good job, participants, especially seniors, sometimes experienced it as an obstacle. They wished to be able to be more spontaneous:

There's a risk that I'll be a bit too prepared, that's a problem if I've already given a lecture and am going to give the same lecture again. I find that horribly difficult, I'm tired of myself, say the same thing I've already said though for the audience it's new of course. However, I find it very difficult to find the right mood while getting things ready, that is, I think I transmit a feeling that I'm not finding it any fun or interesting like I do when I'm more spontaneous. (13)

Both of these interview extracts emphasise the academic, in his/her teaching role, as performer. They imply that there is a risk to be avoided, whether by preparing carefully or by trying to be open. 


\subsection{Learning to Communicate Clearly about Intended Learning Outcomes (ILOs) (B)}

Participants described situations when they had experienced highlighting the course's ILOs as an effective pedagogical tool in helping the students' learning process. A common way was to discuss the ILOs in the introduction to the course:

One of them came and said 'I think it's really good that you're running through the learning goals with us'. I was very explicit when I explained the point of the learning goals. We compared the verbs used in the goals, like in the earlier part of the course the verb was to describe and in this part the verb is to compare. That's more advanced and means you must think about it, to first list the contents so as to be able to compare them.

Here, while focus is on giving the students the best opportunity to do well in an examination, focus is still on the academic taking control of the situation. Risk of failure for the students is being avoided.

Additionally, some participants described positive experiences gained from using the ILOs as a point of reflection and guidance for students throughout the course:

I got a good idea about how to use the learning goals, which was to bring them up again at the end of the course and relate them to the coming exam. I asked the students: 'What questions should I ask so that you can show that you've achieved the learning goals?' |... First they seemed slightly confused. They had to reflect and discuss what might be relevant questions. I also asked them to consider the course literature. They sat and talked for a while, and maybe about 10 different questions came up. Afterwards I realized that I should have asked them to write them on the whiteboard as well so they would have been clearly visible to everybody, but unfortunately I didn't. (16)

In this case, the situation also gave rise to an unexpected learning outcome. Having realized that an opportunity had been missed in not recording the questions that students had produced, the same exercise was repeated with the next group of students. This time, not only were the questions recorded, but they were also published on the university's learning management system, allowing students to use them when preparing for their examination. Again, student success is being supported, risk of failure avoided.

\subsection{Learning When Introducing a Different Pedagogical Approach (C)}

Some of the learning situations that came up in interviews were situations when participants had introduced students to new pedagogical activities or when they had taught in a way that was at odds with teaching norms.

There were stories about implementing new and different pedagogical approaches or tools as well as descriptions of how academics made use of their own experiences of having been students themselves. There were both positive and negative experiences to learn from. One description of a student group having a rather fixed expectation in general of what university studies should be like gave rise to a negative learning experience. Some had enthusiastically tried something they believed could be pedagogically beneficial but had instead met hesitance, resistance and anxiety among the students. Lessons learnt showed that when introducing new and different pedagogy, academics had to pay attention to the students' expectations and customs, introducing new approaches slowly and carefully:

I've tested courses in which I've let the students lecture, it didn't go at all well, the students didn't like it at all, they expect an academic on the podium, and if you're going to come up with new ideas then you have to do it rather carefully. If you're going to change a custom or anything then there's a threshold that you have to cross, their need to see and accept that this new scheme is a good thing $|\ldots|$ one gets the feeling from the atmosphere in the classroom that this is not popular at all. (3)

In contrast, challenging yourself and the students was described as a way to keep up an interest for learning. This situation shows that a minor change in pedagogy can make a huge impact:

I gave some lectures recently at the end of the autumn in which I didn't use PowerPoint at all, more than that I had PowerPoint open to show certain things, but mostly I wrote on the board and discussed things instead $|\ldots|$ their response to that was very positive, I've never experienced anything like it before, there were lots of students who came forward after the lessons and said that this was really good. (2)

When accounting for situations that opened up for student involvement, participants stressed that it required a certain amount of courage on their part:

I've learnt that it's a good thing to involve the students, because then they feel that there are more fun things happening in the room compared with if it's just me talking. When I was new as an academic I wondered 
what would happen if I got questions I couldn't answer, you know, you want to appear as an expert, don't you, and taking the step to problem-based learning, now that felt a tiny bit insecure. (19)

The lessons learned in this theme concern taking account of students and their assumptions about teaching, as well as accepting the challenge and its outcome. When paying attention to the concerns of students', the risk of failure is reduced.

\subsection{Learning to Transform Teaching towards Student Learning (D)}

Many participants made the connection between the development of their own pedagogical competence and an increasingly student-centred approach. They acknowledged the value of interactive learning and gave many examples of situations when they had realized the importance of inviting the students to take part in discussions, listening to how they reasoned, problematized and reflected. The following two interview extracts explicitly illustrate the academic learning about student learning:

I've learnt a lot about this business of letting the students problematize things $|\ldots|$ instead of us as academics communicating knowledge. I've modified that picture quite a lot over the years. (15)

Just listening to the students. It's a matter of preparing oneself very well but at the same time trying to integrate the students' questions. That is, they put questions to you for a reason, if one of them asks something you can be sure that others are wondering the same thing. I try to make use of those comments in my lecture notes for the coming year. (18)

A commonly described positive side effect of actively focusing on the students' learning was enhanced confidence among the students in their own ability. The participants described situations when they were able to feed students with a belief that the students themselves were just as capable as the academics of creating good teaching situations. A positive effect of this was that students were encouraged to give up-front and valuable feedback. One participant described a case in point:

I said: We'll look at the articles one by one, and it'll be like a kind of story about each article: why have they written this, what did they want to say, what are the important concepts and what could you say was the point of the whole thing at the end? And so I also drew on the board. Then one student said: 'this is very good, this has helped me enormously. When you talk about these comparisons, you point at the board, then you say, yeah, if you look at this and compare it with the other'. But then the student said: 'the only thing is that when I'm writing things down at the same time I can't see what you're pointing at $|\ldots|$ It would've made such a difference if you said instead what you were pointing at'. What fantastically fine feedback and with very small, simple changes I can modify my method to make it more suitable, to help the students. (5)

An important prerequisite for student-centred learning was often described in terms of academics accepting that they are not the only expert. It was somehow found a relief to be able to view the teaching situation as a team assignment in itself where different perspectives and knowledge contributed to deeper learning. Furthermore, students became aware of their own responsibility for their own learning.

Another positive side effect of student-centredness experienced by participants was that students were forced or encouraged to actively help each other in understanding and interpreting the content. This was described as beneficial to them both in terms of attaining deeper learning and passing their final examination:

They are forced to become acquainted with the theories. There's a great advantage in giving them the introductory assignments to be solved in groups; they help each other to understand the theories while talking to each other about them. They create their learning during conversation $|. .$.$| I can't supply them with the$ whole truth about our subject, that is, there are masses of aspects that I don't know about, empirical aspects that the students can find out about in much greater detail than I can cover. (20)

Participants who express such turns to student learning as these are acknowledging the risks that can be associated with creating teaching and learning situations where the students are encouraged to participate more fully, but also acknowledging that at the same time they themselves are able to learn from the encounters.

\subsection{Learning to Contextualise One's Teaching (E)}

Participants had developed various strategies to cope with feelings of insecurity when actively involving students in teaching situations. They generally felt more comfortable with student involvement when, for example, teaching a subject closely related their own field of research or a subject of which they had personal experience. They could 
learn, for example, by asking students to prepare questions for discussion and then using these questions as both context and content in dialogues with the students instead of traditional lecturing, as here:

During the break, the students were given an assignment to consider and afterwards I collected their comments and wrote them down on the board. It's something I've understood later, that it's rather a good thing to do that, so that it's not only me doing the talking but the students are also involved, and it's one of those things I've kept in mind. (19)

A further extension of becoming student-centred concerns being able to contextualise the subject at hand in the space of the students own academic or professional interest when, for example, a course is being offered as a service to other programmes, as this extract indicates:

It was while I was teaching the students of human ecology, when somebody said "well, I don't get at all what this is, when will we use all this?". And I managed to give an example which was relevant for them - I hardly know what human ecology is but I was able to explain why the method was interesting in a way that was specific to their subject. Then I could see on their faces --- you have to find a way for the students to come into your subject, and that's an insight that has grown and grown. (20)

When participants tried to introduce new pedagogical approaches, they also realized the importance of making the students understand what was expected of them. In the following example, the participant described the importance of contextualizing and preparing students for an assignment, which in this case was group work in small teams:

We talked about the advantage of learning to be better at working in a group since that's most often the way they'll be working when they enter business life and management $|\ldots|$ on the first occasion they also have to write a group contract that states what each one is expected to accomplish $|. .$.$| how do we go about our work,$ how do we allocate the tasks, how can we be punctual and keep our deadlines? (15)

Contextualising in such ways is effective for understanding where the students are coming from and guiding them to where you would like them to be. By guiding the students, academics diminish the risk of having students not knowing the context and purpose of their studies - an important prerequisite for learning.

\subsection{Learning to Cope with Students' Disappointment and Frustration $(F)$}

Conflicts with students, or facing students' disappointment or frustration, was a recurrent theme in participants' stories. One described how she/he had to handle an entire group of disappointed students and how challenging it was. The students were upset with an examination and even though it was tough to tackle the situation, it went well due to an open-minded approach, allowing both the students and the academics to express themselves:

There were about 70 of them perhaps, I found it tough having to go in there but it turned out very well because I was very open about how we were now going to talk about what we had done and how the exam was $|\ldots|$ that is, in some way a bit kind of therapeutic, so that they were able to express that they were angry or upset but at the same time so that it gave my arguments space too, not at all in any angry tone. (5)

The importance of communication with the students in order to prevent and solve conflicts was acknowledged by the participants. They gave several examples of shortcomings and the need to be precise and explicit about what was expected by different stakeholders. A first necessary step, often mentioned, was to make oneself see things from the students' perspective - sometimes a challenging task.

An area commented on by many participants was students' dissatisfaction with their grades. According to the academics, it was possible to diminish such disappointment by better communication, initiated beforehand, clarifying expectations:

I've pondered over what makes an essay good, what makes it a good piece of work and how should one communicate this to the students? Not just to say that we expect you to do a good piece of analysis. Well, what is a good analysis? Nowadays I go through things much more at the beginning of their courses, like: what makes a good report? How should you deal with references? And how should you think when answering an exam question? What is it that will give you top marks? In other words, I try to get them to understand $|\ldots|$ to make it all transparent. (12)

Another lesson learnt was about forwarding issues to the correct person in charge of making decisions, instead of trying to tackle them oneself. This was found to be especially important when academics already had a teaching relation with a student: 
Well you know, once I had a student in my office who wanted higher grades $|\ldots|$ and he refused to leave my room. In the end I was actually compelled to call a colleague who came into my office and helped me to make the student leave and then I sat for several hours afterwards trying to work out how to avoid similar situations. I've also talked to colleagues about how they handle things and I've really learnt quite a lot from that $|. .$. what I should have said was: 'you can go to the examiner', but then I didn't know that I could have referred him to the examiner. If I'd known, it would have been a bit easier to solve. (9)

Having trustworthy colleagues close by was found to be important in such situations. Although described in the example above, as well as the importance of comfort from supportive colleagues, it was rarely the case that academics felt they received the support they needed. The most common explanation given was lack of time and that mutual support activities among academics were not organized or prioritized by the management. Academics probably had to tackle feelings of distrust on their own.

The example that follows describes how an academic can be emotionally affected when facing their own shortcomings, especially for a senior academic with many years of teaching experience:

I suppose it was confirmed for me that I was able to teach that stuff, although they found it rather difficult, that I was able to teach something abstract, I was able to make it concrete $|\ldots|$ it has led to me sometimes challenging the students rather too much and then they get a bit grouchy and sullen and give me low marks in course evaluations $|. .$.$| it was then I discovered my weaker side, which is: oh dear, how deeply I got affected$ by that. This result was totally unexpected, and there was me believing I was so good at that stuff. (16)

Having a network of trustful colleagues as well as on beforehand discussions, about feelings that could follow after being commented or criticized, could help diminish the risk of leaving academics on their own, sorting feelings out.

Participants also discovered the importance of not only giving critical feedback to students. In an academic setting it was easy to focus on areas of improvement. Even though it was done with the purpose of being constructive, the pedagogical result could be the opposite. As shown below, the participant had learnt from a situation when well deserved, balanced feedback was not given to a student:

There was the occasion when one student reacted very strongly at an essay seminar. There were two of us academics and one student, it was a good essay. We were very critical at the seminar when we asked questions, my colleague and I, and then when we had finished the student spoke up: 'couldn't you have said something positive, it was all just criticism, that essay got a pass but you couldn't find anything positive to say'. I reacted very deeply to that. Now I think about giving both positive and negative critical feedback. (8)

\section{Discussion}

During the interviews it became clear that the majority of the participants had not previously reflected to any significant extent on what they had learned from the teaching situations they had experienced. But it also became clear that they had had several valuable experiences which they were able to articulate, had learnt from them, and had changed their pedagogy as well. Furthermore, it was clear that the participants appreciated reflecting upon such issues.

Our study serves to describe practical teaching situations that show when and how academics learn from teaching experiences, as well as what they learn from those situations. McAlpine and Weston describe learning through reflection on teaching as a process of monitoring actions to track the achievement of goals both during and after the act. During this reflection and monitoring, in terms of earlier experience, knowledge and external cues, decisions to modify teaching, or not, according to the "corridor of tolerance" occur (McAlpine \& Weston, 2000).

Our study shows that academics had experienced learning grounded in their practice that was ready to be transformed into knowledgeable teaching and learning outcomes, which could thereby contribute to a deepened understanding of working conditions for academics, as called for by Malcolm and Zukas (2009). A forum for articulation and discussion was, however, absent.

\subsection{Reflections on the Themes Relating to Learning in Practice}

We identified six themes and have ordered them in accordance with two general dimensions. On the one hand, there is a shift from a focus on the teacher and the teacher's performance to the students and creating situations for their learning, and, on the other hand, there is a move from caution to taking and coping with risk.

$A$ : Learning that preparation promotes an open approach and gives confidence

$B$ : Learning to communicate clearly about intended learning outcomes 
$C$ : Learning when introducing a different pedagogical approach

$D$ : Learning to transform teaching towards student learning

$E$ : Learning to contextualise one's teaching

$F$ : Learning to cope with students' disappointment and frustration

In Table 1 we arrange these themes to indicate the development.

Table 1. The six themes, arranged with regard to their focus on risk and on students.

\begin{tabular}{llll}
\hline & $\begin{array}{l}\text { Focus on teacher } \\
\text { performance }\end{array}$ & Focus on students & $\begin{array}{l}\text { Focus on student } \\
\text { learning }\end{array}$ \\
\hline$A$ & & \\
Avoiding risk & $B$ & \\
$C$ & $D$
\end{tabular}

Open to risk

$E$

F

The first theme, A (1.1), is concerned wholly with what the academic will, or wishes to, perform for the students and avoid a situation where there is any conflict of interest. This is not say that there is no thought at all for what the students might learn thereby, but that is not the main concern. In themes B (1.2) and C (1.3), focus turns to the teaching situation, where students are most certainly present, but risk is being averted. In theme B, the academic is prepping the students for what content is expected during the coming weeks of the course or what is to be examined, and in theme $\mathrm{C}$ risk associated with new pedagogical initiatives is to be avoided, possibly by warning the students about what they should expect. In theme D (1.4), focus turns to the students and their perspectives and input are to be taken seriously, even as supporting the academic in the teaching role. In theme E (1.5) there is a shift to deliberate consideration of student learning whereby their own experience is brought into the teaching and learning situation. The final theme, F (1.6), can actually relate to any of the three features of the dimension of teacher-learner focus, stressing as it does the ways in which academics can alleviate and cope with risk.

The rest of the discussion will focus on some overarching themes of this study. As already mentioned, the categories we arrived at in our analysis distinctly show two dimensions. One stretches from focus on the teacher and the teacher's performance to the students and their learning, and the other goes from avoiding risk to acknowledging and coping with risk. In the following discussion we pick up on these two aspects of the results. In addition, and first, we will take up the general feature of communication as an important feature of pedagogical development.

\subsection{Communication as a Feature of Pedagogical Development}

The results clearly show that the participants had learnt that communication was an important ingredient of their pedagogical competence, not only in the context of presenting new knowledge to students but also in more peripheral features of teaching such as communicating expectations and giving good feedback. Such communication skills were needed to create a good learning environment. Communication can be said to have failed when students are unaware of course intentions, even if academics consider that all is clearly set out in relevant documentation. Such communication needs to extend from the first meeting with students throughout a course, to enhance learning. The work of Bovill et al. supports these findings (Bovill, Cook-Sather, Felten, Millard, \& Moore-Cherry, 2016) in their description of the process of achieving transparency in the teacher-student relationship in order to overcome challenges of discrepancy, and achieve pedagogical improvement.

Another learning outcome related to communication was that participants reported having learnt to express themselves in a more balanced way in their criticism of students, pointing out both strong and weak points in their performance. They had learnt that it is easy for an academic to fall into the trap of stressing weak points at the expense of strong ones. Being critical is part of academic culture but bringing forward merits also promotes learning and a good pedagogical situation. Ramsden (2003) and Ramsden et al. (2007) highlighted the interaction between academics and students leading to pedagogical development, especially the importance of giving students feed-back that is relevant in terms of both content and timing. This is in line with the results in this study and has also been stressed by others (Gibbs, 2013; Knight \& Trowler, 2000). 


\subsection{Awareness of the Students' Perspectives as a Way to Pedagogical Development}

One result that emerged from the interviews is that academics can learn by paying attention to questions from students as well as students' reactions to different approaches, as reflected in themes C and D; student involvement can even be seen as a valuable way towards pedagogical improvement. That participants reported positive experiences of paying attention to the students' and involving them is supported by earlier studies (Marton \& Säljö, 1997; Sierra, 2010). Students' realization that they have to take responsibility for their own learning, that no one can shoulder someone else's learning process, is an important message to reinforce; doing so can be an important step in the effort to develop pedagogy, well in line with other higher education research (Ramsden, 2003; Ramsden et al., 2007). Another reported positive effect of student involvement is that students become motivated to help one another more actively. Apart from the benefits of having a student explaining something from a student point of view, bringing their perspective into the situation, it also decreased the pressure on academics who were not alone in having to provide help or explanations. Further, it was clear that academics can develop their view of the teaching assignment as such, seeing it as a cooperative activity in which they primarily shoulder the role of academic leaders (Ramsden, 2003; Ramsden et al., 2007; Trigwell \& Prosser, 2014). These results contribute to the discussion about the risks of involving the students, in the fear their involvement could diminish the role of academics (Biesta, 2005).

Another aspect related to active awareness of the students' perspectives revolved around paying attention to the students' fields of interest, as in theme E. Some participants described their experience of easily improving their pedagogy by simply presenting abstract, theoretical or challenging parts of the course content through illustrative examples of relevance to the students. This result could be seen as an aspect of constructive alignment often referred to in relation to students' learning (Biggs, 1996), as extended by Trigwell and Prosser (2014) to emphasise the holistic demands of such alignment. By taking the perspective of the students, academics found they could close learning gaps and attain alignment. Recent work by Maton and colleagues (Maton, 2009) on the notion of semantic gravity also aligns with this feature of focusing on students' and their learning, in that bringing students' own experience, outside the realm of the current course of study, better prepares them for the re-contextualizing their knowledge in the world outside the university.

\subsection{Risk-Taking as a Feature of Pedagogical Development}

Another of academics' learning outcomes revolved around pedagogical development that involved risk-taking, being forced to step outside their comfort zone, reflected in theme $\mathrm{E}$ and $\mathrm{F}$, while themes A through D distinctly avoid risk in one way or another. Theme F, dealing with ways of accommodating and dealing with the outcomes of risk-taking, could equally well apply to any of the three focuses on students, and rather reflects collegiate relationships. In line with Le Fevre (2014), the participants described pedagogical development and risk-taking as going hand in hand. Trying a new pedagogical approach could end up with disappointed students or damaged self-confidence. However, there were also reports of finding ways to mentally prepare themselves beforehand, and of developing a sense for approaches to testing something new, in line with Kolb's (1984) learning cycle. Participants described situations of learning from colleagues but more systematic peer support was rare in the context where these particular business administration academics were teaching.

There was a sense that the participants had learnt that it is better to introduce a new approach when teaching in areas they were familiar with and knowledgeable in. Thus, experience was seen as a pre-condition for taking risks but it was also spoken of as being a burden - for example, experienced teachers could sometimes find it hard to encourage themselves to take new initiatives.

\subsection{Recommendations}

When we consider our results and the potential for development of academics' teaching skills we have seen there, we are tempted to offer recommendations for supporting such development. One essential question, however, concerns how and in what respect leaders in academic environments could support experience-based learning and promote pedagogical development among academics.

Our first recommendation is to offer opportunities to satisfy the need and desire among academics to take time to reflect upon their own experience-based learning in order to contribute to their pedagogical development. An occasion to articulate specific events and their outcomes can be valuable for themselves as well as others. This is congruent with claims from other researchers (Daniels, 2017; Kemmis, 2012; Kolb, 1984) that show that when academics experience, test and refine their own practice, they promote pedagogical development and achieve increased competence. If they do not do this, valuable insights achieved from the pedagogical practice itself will 
probably get lost, which can in turn harm the important development of academic communities, as stressed by Leibowitz (2014).

Secondly, there is a need to make the valuable opportunity to articulate and reflect on experience more widely and routinely part of academic life, as part of normal teaching responsibilities. For example, bringing those currently teaching a particular cohort of students together over lunch or coffee to discuss their experiences. Or, team assignments could be valuable in which a group of colleagues, involving juniors as well as seniors with different perspectives and experiences, can act as mutual support and buffer as well as guarding against pedagogical stagnation that risk-avoidance can cause. Providing a supporting environment as suggested by Le Fevre (2014) could empower academics to take risks in favour of new pedagogical initiatives, thereby shaping a continuous cycle of improvement as suggested by Vithal (2016). However, to achieve a collaborative environment, also engaged and supporting academic leadership is needed as highlighted by Vithal (2016:13): “...taking responsibility for change and innovation are especially important in respect of the T\&L academic leadership who must actively support and value the initiative or policy that embeds SoTL."

If such moves are to be made, whether across whole institutions or within particular departments of the university, demands are placed on the higher education management therein, their knowledge, ability and power to oversee and change the structures and time constraints in their domains.

\subsection{Concluding Remark}

This study contributes several examples showing how pedagogy has the potential to develop if academics are encouraged to become aware of and reflect upon what is happening in the teaching situation. However, experience-based pedagogical learning requires better recognition by higher education management in terms of leading the organization and giving it time. How to make that happen is an important area for further exploration.

\section{References}

The Swedish Higher Education Act.

The act of ethical trail of research concerning humans.

Biesta, G. (2005). Against learning. Reclaiming a language for education in an age of learning. Nordisk Pedagogik, 25(1), 54-66.

Biggs, J. (1996). Enhancing teaching through constructive alignment. Higher Education Research \& Development, 32(3), 347-364. https://doi.org/10.1007/BF00138871

Bovill, C., Cook-Sather, A., Felten, P., Millard, L., \& Moore-Cherry, N. (2016). Addressing potential challenges in co-creating learning and teaching: overcoming resistance, navigating institutional norms and ensuring inclusivity in student-staff partnerships. Higher Education, 71(2), 195-208. https://doi.org/10.1007/s10734-015-9896-4

Daniels, J. (2017). Professional learning in higher education: making good practice relevant. International Journal for Academic Development, 22(2), 170-181. http://dx.doi.org/10.1080/1360144X.2016.1261352

Ellström, P.-E., \& Kock, H. (2011). Formal and integrated strategies for competence development in SMEs. Journal of European Industrial Training, 35 (1), 71-88. https://doi.org/10.1108/03090591111095745

Eraut, M. (2004). Informal learning in the workplace. Studies in Continuing Education, 26(2), 247-273. http://dx.doi.org/10.1080/158037042000225245

Gibbs, G. (2013). Reflections on the changing nature of educational development. International Journal of Academic Development, 18(1), 4-13. http://dx.doi.org/10.1080/1360144X.2013.751691

Kemmis, S. (2012). Researching educational praxis: Spectator and participant perspectives. British Educational Research Journal, 38(6), 885-905. https://doi.org/10.1080/01411926.2011.588316

Knight, P. T., \& Trowler, P. R. (2000). Department-level Cultures and the Improvement of Learning and Teaching. Studies in Higher Education, 25(1), 69- 83. http://dx.doi.org/10.1080/030750700116028

Kolb, D. A. (1984). Experiential learning : experience as the source of learning and development. Englewood Cliffs, N.J.: Prentice-Hall, cop.

Le Fevre, D. M. (2014). Barriers to implementing pedagogical change: The role of teachers' perceptions of risk. Teaching and Teacher Education, 38(Feb), 56-64. https://doi.org/10.1016/j.tate.2013.11.007 
Leibowitz, B. (2014). Reflections on academic development: what is in a name? International Journal for Academic Development, 19(4), 357-360. http://dx.doi.org/10.1080/1360144X.2014.969978

Malcolm, J., \& Zukas, M. (2009). Making a mess of academic work: experience, purpose and identity. Teaching in Higher Education, 14(5), 495-506. http://dx.doi.org/10.1080/13562510903186659

Marton, F., \& Säljö, R. (1997). Approaches to learning. In F. Marton, D. Hounsell, \& N. Entwistle (Eds.), The Experience of Learning. Edinburgh: Scottish Academic Press.

Maton, K. (2009). Cumulative and segmented learning: exploring the role of curriculum structures in knowledge-building. British Journal of Sociology of Education, 30(1), 43-57. http://dx.doi.10.1080/01425690802514342

McAlpine, L., \& Weston, C. (2000). Reflection: issues related to improving professors' teaching and students' learning. Instructional Science, 28(5), 363-385 https://doi.org/10.1023/A:1026583208230

McAlpine, L., Weston, C., Berthiaume, D., Fairbank-Roch, G., \& Owen, M. (2004). Reflection on Teaching: Types and Goals of Reflection. Educational Research and Evaluation, 10(4-6), 337-363. https://doi.org/10.1080/13803610512331383489

Oleson, A., \& Hora, M. T. (2014). Teaching the way they were taught? Revisiting the sources of teaching knowledge and the role of prior experience in shaping faculty teaching practices. Higer Education, 68(1), 29-45. https://doi.org/10.1007/s10734-013-9678-9

The Higher Education Ordinance.

Patton, M. Q. (2002). Qualitative research \& evaluation methods. London: SAGE.

Price, O. M., Scheeres, H., \& Boud, D. (2009). Re-making Jobs: Enacting and Learning Work Practices. Vocations and Learning, 2(217). https://doi.org/10.1007/s12186-009-9025-6

Ramsden, P. (2003). Learning to teach in higher education (2nd ed.). London och New York: RoutledgeFalmer.

Ramsden, P., Prosser, M., Trigwell, K., \& Elaine Martin, E. (2007). University teachers' experiences of academic leadership and their approaches to teaching. Learning and Instruction, 17(2), 140-155. https://doi.org/10.1016/j.learninstruc.2007.01.004

Sierra, J. J. (2010). Shared responsibility and student learning: ensuring a favourable educational experience. Journal of Marketing Education, 32(1), 104-111. https://doi.org/10.1177/0273475309344802

Silverman, D. (2013). Doing Qualitative Research: A Practical Handbook. London: SAGE Publications Limited.

Trigwell, K., \& Prosser, M. (2014). Qualitative variation in constructive alignment in curriculum design. Higher Education, 67(2), 141-154. https://doi.org/10.1007/s10734-013-9701-1

Webster-Wright, A. (2009). Reframing Professional Development Through Understanding Authentic Professional Learning. Review of Educational Research, 79(2), 702-739 https://doi.org/10.3102/0034654308330970

Vithal, R. (2016). Growing a scholarship of teaching and learning institutionally. Studies in Higher Education, 1-16. https://doi.org/10.1080/03075079.2016.1180350 